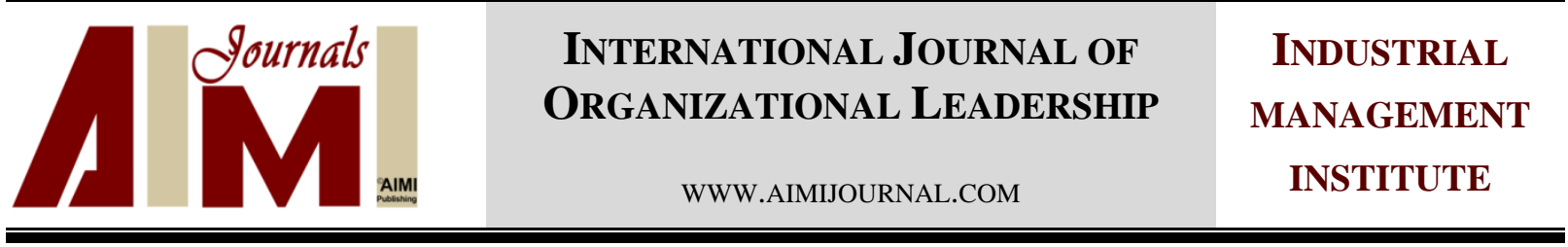

\title{
A guide on taking the leadership of your life
}

\author{
Tobias Ebbing $^{1 *}$, Arne Petermann ${ }^{2}$ \\ ${ }^{1}$ Warsaw School of Economics, Technical University Berlin \\ ${ }^{2}$ Berufsakademie für Gesundheits- und Sozialwesen Saarland
}

Keywords:

Leadership, DecisionMaking, Integrity

\section{Received \\ 27September2016}

Received in revised form 28February 2017

Accepted

08March 2017

Correspondence:

tobias@ebbing-berlin.de

\begin{abstract}
Having control over your life requires selected modern and classical concepts of leadership and tranquillity to assist you in analysing and approaching different situations in life and business. Based on Heifetz (1994) a method of building a distant view on events is introduced to enable more rational decision-making. A theory of contextual awareness is developed based on classical philosophies. Responsibilities in a certain context are identified and classified in order to help you understand the effects of your actions. For proper interaction with the own context, a model of integrity based on Erhard, Jensen, and Zaffron (2014) is suggested. Finally, a selection of sources for strength and courage are introduced to lead us a happy and meaningful life constantly. This paper should serve as an expandable framework for the application of inspired and reflected theories on leadership in the reader's life. Therefore, the present study concludes with recapitulating questions to support putting theories into action and applying the presented instruments.
\end{abstract}

(C)AIMI Journals

\section{Introduction}

We all experience difficult and pleasant situations in our lives. These situations have something significant in common: They let us lose ourselves in emotion. Besides, they are tricky moments of decision-making for us as the impact of our actions is often multiplied in these very moments. However, in these situations, we often lose tranquillity, the term introduced by Seneca the Roman philosopher. "Tranquillity is a certain equality of mind, which no condition of fortune can either exalt or depress” (Hazlitt \& Hazlitt, 1984, p. 12). Seneca further refers to this state of tranquillity as a state of perfection at a similar point. It can be seen as a state where 
your decisions are rational and not biased by emotions they are sustainable because you were aware of their results. It is in this state that you are connected with them, as you actively decided for or against your actions. This desired outcome can only be achieved when you are able to think through decisions in a clear light - a state of tranquillity.

Unfortunately, our lives are occupied by constant movements and activities. To aspire more and remain in tranquillity while keeping track of our purpose and aligning our actions with our main goals, there is an obligation for constant reconsideration of our being and actions. Answers can be found in ourselves if we keep searching for them.

Some of us are constantly looking for answers to very sophisticated questions. Questions like those, Tolstoy's King has asked: "How can I learn to do the right thing at the right time? Who are the people I most need, and to whom should I, therefore, pay more attention than to the rest? And, what affairs are the most important and need my first attention?” (Tolstoy, 1903). The actions of Tolstoy's King revealed that the only time that is important is now, the most important man is the one that you are with, and the right thing to do is to do good to those good who are with us (Tolstoy, 1903). This indicates that the ever-changing circumstances and the constant changing answers to these questions require our frequent revision and reconsideration of the answers we have found.

To evaluate our past actions and to decide our future actions, we need to see life rationally and without bias; but how can we gain distance-how can we re-evaluate what we have done previously, and how can we gain tranquillity that enables us to see the moments of our life clearly and help us to recognise and pay respect to the most important people in our life.

This self-management approach can also be put into a leadership and corporate context: How can we adapt our leadership's behaviour with ourselves, team, and company's thrive in the new environments? How can we return in times of crisis to the fundamentals of purpose, freedom and state of mind? And, most importantly, how can we become an adaptive leader as Heifetz and Linsky (2002) mentioned?

An adaptive leader is a leader that can handle problems that exceed the technological realm. Technological problems can be solved with present knowledge and procedures. Adaptive problems demand innovation and learning (Heifetz, 1994). This adaptive leadership effort requires one to deal with conflicts in the values people hold or to decrease the gap between the values people stand for and the reality they face. Adaptive work necessitates a change in values, beliefs, or behaviour. The exposure and orchestration of conflict-internal contradictions within individuals and constituencies supply the leverage for prepare and organize people [and yourself] to learn new ways (Heifetz, 1994).

A possible approach would be to assess the three questions of Tolstoy in an adequate context. In this case, for example, we might want to ask: How can I, my team, or my company, produce, and promote the right thing in this new environment, at this moment? This certainly is not a new question to you, although it might help you to bridge the gap between the presented philosophical approach and the work in practice. However, in the corporate and personal leadership context, we face the same issue: Evaluating circumstances is made complex because we cannot always explain problems objectively (Heifetz, 1994). We may find ourselves in situations in which we are bound to a certain product by attaching emotional value or to a colleague that became a friend but needs to be let go now. Following this and considering that 
leadership starts with oneself, this question arises that how can we return to a state of tranquility and clarity again? Heifetz advises to achieve this by going onto the balcony (Heifetz, 1994; Heifetz \& Laurie, 2001; Heifetz \& Linsky, 2002). Going to the balcony means to mentally leave the field of action which we will hereafter refer to as the dance floor and then observe. Observe your own play and that of others and examine their interaction and understand connections, so you will become a spectator of your own life and behaviours and you can then evaluate the field of action with a clear and conscious mind. This has become a commonly suggested method of not only inquiring insight into your actions but also as a way to solve conflicts. To summarise, "going on the balcony means distancing yourself from your natural impulses and emotions” (Ury, 1993, p. 55).

The following advice is a guideline for a daily transition from the dance floor to the balcony. They will guide you through a process of viewing things in the state of tranquillity and assessing aspects of your life in a new light. Additionally, they do not only enable you to see things more clearly, you will actually be able to change yourself. After reading this paper, you will be able to act more self-consciously and you will understand what it means to take the leadership of your life and your surroundings. By regularly doing that exercise, you will be always conscious of yourself from both the dance floor and the balcony perspective. Thus your actions will be more concise and on point.

You should practice moving from the dance floor to the balcony for short periods of time during the day - also while doing something else like interacting with people. It might be helpful to develop a trigger, like folding your hands, at which you always move to the balcony. It is advised to move "your chair a few inches away from the table” (Heifetz \& Linsky, 2002, p. 7) to step on the balcony during the action, you should find your own method. Keep in mind that it should be possible to use it at any time and it should not be awkward but invisible or even a posture of assertiveness. That is why folding your hands can be a good trigger.

With a newly developed high-level of reflection and perception of yourself, you may "begin to act as if you are indestructible: But the intellectual, physical, and emotional challenges of leadership tend to be fierce. To this end, in addition to getting on the balcony, you are required to often step into the inner chamber of your being” (Heifetz \& Linsky, 2002, p. 10). If you fail to do this, "your seemingly indestructible self can self-destruct” (Heifetz \& Linsky, 2002, p. 10). The current article provide advice on insights related to your inner chamber to strengthen and empower your actions. At the end of this paper, you will be left with a story of empowerment and a feeling of sublime grandeur. From now on, be aware that what is happening in your inner chamber will not dictate your behaviour on the dance floor anymore. You will start to view these two concepts as separate entities; one not necessarily preceding or causing the other, but remaining in a balanced relationship of energy giving and taking.

\section{Looking at the Dance Floor - Take the Leadership of your Life}

When looking at the dance floor from the balcony, the primary goal is to acquire leadership of your life. For that, you need to perceive the world and your actions in a state of tranquillity. To do so, you must take your position on the balcony and generally observe three things, namely circumstances on which you are acting, circumstances in which you are acting, and how you occur for yourself in acting on whatever you are acting on (Erhard, Jensen, Zaffron, Granger, \& 
Echeverria, 2013) and how the circumstances you are dealing with [1 and 2] occur for you(Erhard et al., 2013). The third point might need some clarification. "Occurring” in this context does not mean how you feel or felt about something. It is important to remember that you are looking at the dance floor, not into your inner chamber. It is about how the actual reality occurred to you, how you viewed situations and yourself, and how you viewed the circumstances you reacted in and on (Erhard et al., 2013).

You might notice an important distinction here. When going on the balcony and observing the dance floor, you want to separate your perception of reality from what the actual circumstances were. That is, you should remove your filter of occurrence under the given circumstances and how it occurred to you in order to obtain an objective insight.

How things occur to you is the actual source of your being and acting in life. Consequently, having control of how things occur to you will grant you the full leadership of your life (Erhard et al., 2013). Everything you do, every small or significant action, and every decision and thought, is a result of the mere perception that you have on things.

This may be seen in the example of someone who is afraid of dogs. The circumstance on which this person is acting is a stray dog approaching him or her. The circumstance that the person is in is that they are trapped against a wall and a river while being alone on a walk. How will these circumstances occur to this person? What version of reality will be perceived?

For this person that is afraid of dogs, the situation might occur that they will be imminently attacked by the dog. They might attempt to run away and get bitten. How the situation is perceived is the only reason for whatever action will be taken. The reality itself is unbiased. This perception or occurrence of the situation is also the only reason behind them being an "afraid-of-dogs-person". Read the story again, but this time remove the first sentence that includes the information "afraid of dogs" and imagine the situation once more. As you can see, what happens to you is the reason for your actions and your being, not that you simply have a fear of dogs.

You might want to argue that the circumstances occurring as being dangerous are caused by the fear of dogs. If you choose to see situations like this, take care not to victimise yourself, arguing that you are a slave to your feelings; this is indeed the easy path. Think about it again and imagine that the dog is only curious about what you are doing in its territory, and it is determined to mark and defend its property. It is a relative of the wolf and it wants to defend its kids, and simply it wants you not to escalate the situation and only move along. Does the situation still occur as threatening? You can still say that you are afraid of dogs, but how can you describe the situation?

Don't let your fear control you. A better way to see the world would be to redefine fear as a concept in your mind in threatening situations. You should understand this concept is under your control. You may reevaluate how this situation should occur to you in a state of tranquillity. Take your time to understand in and on what you are really reacting on and keep it separate from how it occurs to you. If you find yourself in a situation merely reacting to circumstances - hence losing control about how circumstances occur to you - stop reacting. Instead, go on the balcony for an "extraordinary session" and get a "distanced view of close things”(Ury, 1993, p. 55).(cf. Ury, 1993, pp. 54-56). 
When standing on the balcony, regularly or irregularly, look at the circumstances straight and unemotional. Understand how they occur to you. Discover the difference between how they occur and the circumstances themselves. Once you realise that your being and actions are the results or reactions of how things occurto you, you might discover that you can start taking full control of them. If you address the source of your being and actions and how things occur to you instead of how you want to react to them, you will be able to improve your actions and being. This means you can now take leadership of yourself and your actions by altering the source of it.

Telling yourself to be brave or more attentive at meetings might work in the short-term, but it will make you unhappy as you work against your wishes. You need to understand what you are acting on and in while understanding the occurrence-filter that you apply to the circumstances. Work on how these situations should occur to you. Think of the dog in the intriguingway described above.

\section{Understand and Control Your Context to Generate Freedom}

What you primarily have learned in the previous section is to take control of the context that you create for yourself. This context can be seen as the combination of circumstances on and in which you are acting and how it occurs to you. By changing how things occur to you, you actively create your own context. However, you should be aware that this is not yet happening for a variety of reasons. Most of the time, we tend not to be aware that we are always creating a context for ourselves. We need to bear in mind that all reality we perceive is only affecting us in the way that it occurs to us. In other words, everything in life is subject to the perception filter, even if we have not looked at it yet in a state of tranquillity, and therefore, we have not recognised the filter. As it is stated by Marcus Aurelius: "Life is opinion” (Hazlitt \& Hazlitt, 1984, p. 135). If you wish to live a happier life and you want to take leadership towards that, you should pay attention to how much you complain about things that happen in your life. This complaining indicator may provide insight into your progression towards happiness, and you may improve this by evaluating or actively changing your "occur" filter, in regards to the occurrence of complaining. Whenever you complain or hear people complain, it is, like everything, a result of how things occur to us. In the pursuit of a happier life in tranquillity, we are interested in changing the cause of the complaining. This cause is often not the circumstances themselves, but how we perceive these circumstances. In this regard, Marcus Aurelius argues that "take away thy opinion, and then there is taken away the complaint [...] Take away the complaint, [...] and the harm is taken away. [...] Everything which happens, happens justly, and if you observe carefully, thou wilt find it to be so" (Hazlitt \& Hazlitt, 1984, pp. 135-136).

Remember, circumstances are neither good nor bad: They simply are. Whatever it is that makes you complain is how these circumstances occur to you. Also, problems do not exist per se; only circumstances exist. You make them occur to you as problems for you. And now, having understood this, the duty is yours to change your filter. It will give you more than you think. For example, it gives you freedom to choose in basically any situation you are facing. For "one cannot make a slave out of a free person, for a free person is free even in prison, if a person tries to change external reality by being out of prison in order to be free, he is a prisoner 
indeed, [as] freedom lies not in external circumstances; freedom resides in the heart” (De Mello \& Stroud, 1992).

Leadership starts with yourself but does not end there. It is commonly understood that to be an exceptional leader you should not only be able to create and control your own context but also instil context into your followers like your team or company (Heifetz, 1994; Kotter, 1995). This opens a new set of responsibilities that you must be aware of.

\section{Map and Take Charge of your Responsibilities}

As a leader, you have to be aware of the responsibilities that others expect from you; but first of all, you need to be aware of the responsibilities you have towards yourself. You have just learned that one of your responsibilities is to build circumstances for yourself to excel your activities. It includes taking good care of yourself in terms of mental and physical health as it is your responsibility to empower your capabilities to reach your desired maximum. This similarly applies to your personal and professional life.

You are then responsible for your own activities, as they are the reflection of you on this planet, and everything and everyone you affect. Your actions are the connection between you and this world. As you will learn when dealing with the topic of integrity, they are the only things that count for anything and anyone outside yourself. In consequence, you are responsible for everyone that is affected by these activities. Among these, for the third time, "the most necessary man is he with whom you are, for no man, knows whether he will ever have dealings with anyone else" (Tolstoy, 1903). From that person(s), you may widen your circle of impact in waves. You will see that there are people and things that are directly and indirectly affected by your actions.

For example, firing an employee that is emotionally close to you might directly affect your relationship with that employee. However, your action has further impact. The most obvious one is the life of the family of your employee. A more abstract impact (when not hiring a substitute) would be the loss of tax money for the state. Part of that was intended for elderly pensions and hence your action may partially contribute to something else, for example, a pension freeze in the next year. You will usually see this pattern in many of your impact analysis as it results from the network structure. Therefore, there is an exponential increase of unwilling or willing acceptors of your actions.

By looking at your responsibilities, you can see that you are in charge of the consequences of your actions every moment. You need to make sure that your responsibility is not reducing in the intervening years. It might even amplify itself. A decision should never be made if you have to justify it in a way which indicates that you would not want to bear the consequences. It should be made with respect to the passing of time and if you justify it with the fact that you will not be around anymore to face the consequences, you have chosen the coward's way out, not a leader's way. Just imagine your regrets when you look at your kids at the moment of death. Realising the mess you have left them, remember you are responsible for more than yourself and there will always be someone or something that is going to be affected by your actions. Never assume that you can hide from your responsibilities in the course of events.

This is the negative side that needs to be taken into account. You should also know and reassure yourself of the fact that the consequence of your actions would definitely affect the 
life of all people you are responsible for. Anything you do or decide not to do, can and will affect the course of events. Your impact is not limited by time and it may grow with it. You are able to change the course of history with each and every action you do now. So, go out and change your own history and the history of everyone that is affected by your decisions. You have incredible potential in this very moment and every moment that has passed, and you will have it in every single one that will come. Remember, it is always now and it is the most important time because it is the only time when we have any power (Tolstoy, 1903). Do not confuse power here with the power of the effect of your actions and do not waste it by thinking you are not here long enough to see the outcomes. Also, do not waste it by thinking you could not affect anything because you cannot see your influence right now. Remember the longer you put your mind on any one thing, be it evil or good, the stronger you make it as an unseen reality. It must at last, as you keep it in mind or put your mind on it, make itself in the scene and physical world [as] an agency for pain or pleasure (Mulford, 1886).

Figure 1 represents the responsibility network.

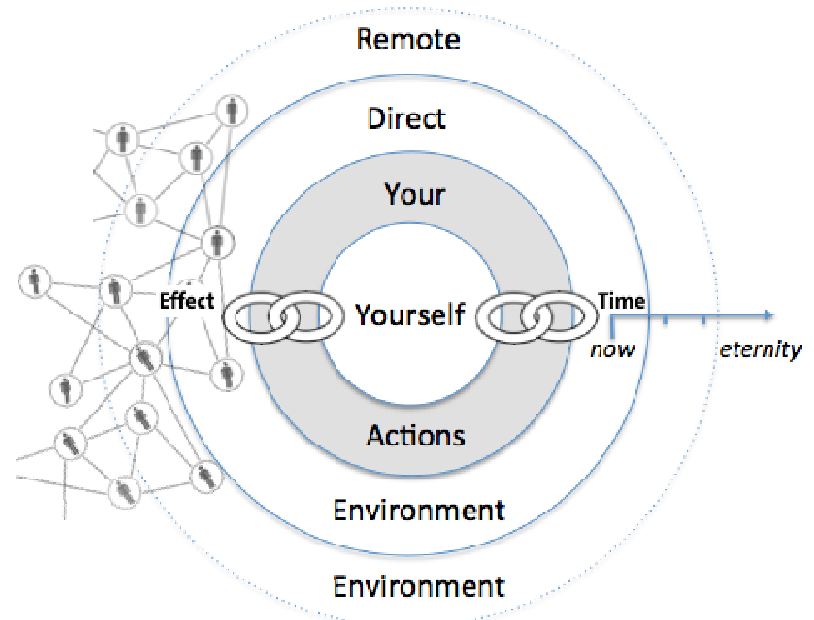

Figure 1. Responsibility network by the Author

Now you might ask yourself how you should behave and how you should cover this responsibility that you have and you might even see it as a burden. Be assured that it is easy and again, only a way of your "occur"-Filter. Make yourself aware that you have been influencing your responsibility network all your life, and likely, light-handedly. Compare this light-handed treatment of so many things and the life that you influence with the 'burden' you see now. With your decision to take leadership of your own life - and subsequently the life of others too, you must be aware and not be blindfolded. Take it as a chance to manoeuvre your actions into the proper long term direction.

Also, remember that you are in the responsibility network of other people too and that you are responsible for being in that network as you are responsible for creating your environment. It is, therefore, your responsibility to take care of being in a network of positive effect impact and the other way around, at the same time building one for others. As it is widely known that 
you want to surround yourself with people that seek to do good to you. Also, extend this to surround yourself with people that not only do good things but the ones that you can and you want to do good for them as this will maximise your impact. Surround yourself with a network of people that, aware of it or not, benefit you with their actions and that you can benefit with yours wherever you can. Build a network of symbiotic benefit and you will exponentially increase not only your impact but also your overall life happiness while reaching it.

Keep in mind that while it is tempting to go alone, it is also foolish (Heifetz \& Linsky, 2002), especially for your professional leadership practice, but also for your personal quests. Actively search for supporting network environments, create a supportive environment for yourself, and be part of a supporting environment for others.

\section{Build a Positive Concept of Integrity and Obey It}

After you have developed a routine of going onto the balcony, it may be that observing your integrity might still be one of the hardest tasks to do. To do so, you have to match your activity on the dance floor not only with the future, present, and past plans that you have (had) but also with your inner chamber. This section is therefore positioned at the transition between both parts. Also, assessing it will most likely greatly challenge what you perceived as integrity in the beginning. Furthermore, you might find yourself fighting against it, as keeping integrity means also putting all things that you said and thought during the previous sections, and probably your past life, literally, and committedly into action.

The following notes will rely on the definitions of Erhard, Jensen, and Zaffron (2014), as their definition is a very logical and workable one, and the concepts of this paper evolve around their leadership theories. The provided concept is perfectly sufficient for commencing your transition. However, for more insights and disambiguation of integrity, you might want to revisit other papers like Audi and Murphy (2006); Bass and Steidlmeier (1999) especially for impact on leadership effectiveness; and Palanski and Yammarino (2009) as well.

When you take some time to define what integrity is for yourself, you will likely find that what you understand as integrity is rather blurrier than it is clear. It might have something to do with being honest and trustworthy in your mind and you might likely attribute these values to yourself as well. What exactly are the components that you assess when assessing the integrity of a person, for example yourself? People tend to attribute certain character traits, perhaps based on convenience of the definition of what e.g. integrity is: But if integrity is a blurry concept it can rarely be ensured that it will be maintained. The temptation may be too great to redefine and adapt the definition according to your current needs in order to stay within what you comfortably define as integrity.

Erhard et al. (2014) defined an extensive, positive model of integrity. Integrity, in its very roots, is the state of not being broken or in other words, it is considered as wholeness. Erhard et al. criticise that this definition is open to individual interpretation as to why you think you have integrity and it is normative but should be positive. This means, it should not be bendable, as a bendable definition of integrity nullifies your integrity by not having integrity in itself. The one and only rule of Erhard et al.'s definitions of integrity is that integrity is honouring one's word. 
In case you wondered what other concepts might be associated with integrity, Table 1 outlines distinctions indicated by Palanski and Yammarino (2009) that might be of help for further reference to the topic.

Table 1

Distinctions Outlined by Palanski and Yammarino (2009)

\begin{tabular}{ll}
\hline \multicolumn{2}{c}{ Comparison of the Current Definition of Integrity to Other Constructs } \\
Integrity Use in org. Literature & Related Virtue \\
\hline Consistency of Words and Actions & Integrity \\
Being True to Oneself & Authenticity \\
Consistent Behaviour in Adversity & Courage \\
\hline Moral/ethical & \\
\hline Honest & Honesty \\
Trustworthy & Trustworthiness \\
Just/Fair & Fairness \\
Caring & Compassion \\
Wholeness & Character \\
\hline
\end{tabular}

However, the definition of Erhard et al. (2014) leaves parts open for some interpretation: firstly, what your word is, and secondly, what honouring means. The following list defines what your word means and where the points are taken from. The explanations are a remark of the author of this paper based on the original papers noted below.

- "What you said” (Erhard et al., 2014)

- "What you know" (Erhard et al., 2014) already now about the word you have spoken

- "What is expected" (Erhard et al., 2014) of you (unexpressed requests of you) by all those with whom you "wish to have a workable relationship" (Erhard, Jensen, \& Zaffron, 2014)

- "What you say is so" (Erhard et al., 2014), or how you described the reality you are or will be in.

- "What you stand for” (Erhard et al., 2014),

- "Moral, ethical, and legal standards” (Erhard et al., 2014),

Having defined your word, it is also necessary to define how to obey it and how to deal with situations in which you are not able to keep your word, while still maintaining integrity. Erhard et al. (2014) basically advise to keep your word when you give it and as soon as you know that you cannot keep your word, inform the parties that may be concerned about the consequences as such - as well as yourself, about the situation (Erhard et al., 2014).

Erhard et al. (2014) also shed light on a collection of certain factors that may build a veil of invisibility and may challenge you when trying to live up to your full integrity. There are many things that will make keeping your integrity hard, and therefore, it is not easy to uphold and falling out of integrity may be rather easy.

See also Argyris (1991) on defensive reasoning and the doom loop on the issue of admitting mistakes to honour your word. Take your failures in keeping your integrity as things to learn. Therefore, learn how to deal with your failure and accept that you will and do fail consistently; 
and, make use of the lessons of your failures of integrity to improve your being and leadership (Argyris, 1991).

Overall, keep in mind that "Integrity is a mountain with no top" (Erhard et al., 2014). You will fall out of integrity more often than you want to and you need to accept that you can learn from it. That is, integrity should be seen as a process that is not simply a state which can be achieved.

Keep learning with your head high and stay realistic. Apply the highest standards to your word to excel in making decisions and live a life of greater impact and fewer failures by seeing and correcting them. You and your peers will value your integrity as a virtue. Also, you will improve yourself and your impact more efficiently. Most importantly you will also start to be more confident, self-aware, and assured of yourself in any action.

\section{Looking into the Inner Chamber}

The previous sections have provided the tools for you to gain full control and leadership of your life and also the responsibilities that you have. You have been given a positive definition of integrity and now know how to control yourself to stick to your word. You have learned how to lead yourself to become a better you, and consequently, a better leader for your followers. Additionally, you have learned how to execute your abilities in a responsible manner that you will feel empowered and great.

Perhaps you may also soon experience a growing feeling of discouragement. There may be small feeling within yourself when you have realised all your influence and impact. As expected, you begin to act invincible towards the outside world, but at the same time, your inner-self begins to self-destruct, facing the tasks that wait for you while on the outside you gain even more and more confidence, influence, and power (Heifetz \& Linsky, 2002). You may face fear like you have not known it before as you end up doing things that may happen for the first time in your life; so, you may primarily develop doubts in your competencies.

\section{Facing Fear and the Courage to Do So}

Along with your road, you will face fear. It is part of every great leader's life to fear things that will cross their path. Sometime, you will even fear what you are going to achieve, overwhelmed by your creational forces and legacy that follows you. It is almost a self-fulfilling prophecy, as "the more intelligent you are, the greater number of possible fears you will have" resulting out of a higher sensitivity towards everything that the world brings with it that is to fear (Tracy, 2005).

The important thing, though, is to keep facing the fear. Tracy further argues that the easiest way to identify the leader of a herd is to wait until they are attacked. While the herd will run away, the leader will face the fear, risking his life, standing his ground to buy time for the others to escape (Tracy, 2005) but to do so, you need courage. The equation resulting out of this is that leadership needs courage. To this end, it is not only in need of leadership courage to free yourself from fears (Mulford, 1886), nay, great leadership implants courage into the leaders followers, as for example, President Johnson encouraged Martin Luther King to kindle the civil rights movement (Heifetz, 1994). 
No doubt, this is hard and will not get any easier. Your tasks in life will only grow more meaningful, and hence also more uncomfortable. Even your actions may soon seem threatening to yourself due to their sheer vast impact. Therefore, to strengthen your character and leadership skills, you will need to identify and nurse the sources of courage.

Congratulate yourself for any fear you have faced. If you want, create a "Fear Book" to document all the fears you have faced and the sources of courage you used to face them. Identify the most important sources of the courage by quantifying the sources you tap for the biggest problems you have.

\section{Focus and Set Forth on Your Journey}

The longer you pursue these tasks and concepts, the more often you will realise that you may tend to lose focus. You lose focus on the smaller goals or on the bigger purpose of it. Whatever it is, it damages your strength. Therefore, the last advising section of this paper can be both a call to use the balcony time and a guideline to stay sharp on your odyssey towards your goals. There might be tempting offers that will make it hard for you to keep focus or tough roads ahead, but you need to keep in mind why you are doing all this. You need to focus on the purpose of your journey. Withstand the temptation of short-lived pleasure and follow what you truly long for.

Regularly return to a sanctuary that might be a physical place such as the kitchen table of a friend's house or a regular routine like a daily walk through the neighborhood you need to use (Heifetz \& Linsky, 2002) and in that space and time look into your inner chamber. Take your time, evaluate the damage that has been done to you, and then build routines to defend yourself and build up strength. Be open to your own weaknesses but do not get absorbed by them. Lick your wounds for a short while but then gain emotional distance and reevaluate what has happened.

Look at the situation in your inner chamber with the same tranquillity that you learned to use when looking at the dance floor. Realise that in leadership it is not you who is the one that was meant to be hurt by the environment; it is how you affect other people's lives. Any defensive action you might face is the reason for concern, but should not hurt you as your actions are of higher purpose. As you behave with integrity and responsibility for all affected parties, rest assure that you did not do wrong. However, if you did wrong by not obeying the principles of integrity or responsibility, go and excuse yourself by those people to whom you did wrong and talk with them about what went wrong to restore your integrity and wholeness. Visit your inner chamber and sanctuary whenever needed to renew your stores of emotional resources and recalibrate your moral compass (Heifetz \& Linsky, 2002).

And then leave it again with assertiveness, a head held high, and the greater goal in mind. Move on with strength and move back to the dance floor, aware of your strength, source of courage, integrity and responsibilities, awaiting to shape the future, and face the circumstances as a positive challenge:

For further research on the effectiveness and applicability of the theories collected in this work, there are several steps that can be followed. First, an extended version of this collection with recommended tasks and balcony questions can be developed. The collected tasks and questions should be tested on whether a notable improvement of life's quality and leadership 
skills can be found after following them. Based on such a collection, a course on taking leadership of one's life can be designed.

\section{References}

Argyris, C. (1991). Teaching smart people how to learn. Harvard Business Review, 4(2), 4-15.

Audi, R., \& Murphy, P. E. (2006). The many faces of integrity. Business Ethics Quarterly, 16(1), 3-21.

Bass, B. M., \& Steidlmeier, P. (1999). Ethics, character and authentic leadership behavior. The Leadership Quarterly, 10(2), 181-217.

De Mello, A., \& Stroud, J. F. (1992). Awareness: A de Mello spirituality conference in his own words. New York: Image Books/Doubleday.

Erhard, W., Jensen, M. C., Zaffron, S., Granger, K. L., \& Echeverria, J. (2013). Temporary and Progressive Slide Deck for Course Participants in'Being a Leader and the Effective Exercise of Leadership: An Ontological/Phenomenological Model. University of British Columbia, Vancouver, Canada. http://papers.ssrn.com/sol3/Delivery.cfm?abstractid=2248706

Erhard, W., Jensen, M. C., \& Zaffron, S. (2014). Integrity: A positive model that incorporates the normative phenomena of morality, ethics, and legality Abridged (Harvard Business School NOM Working Paper No. 10-61).

Hazlitt, F., \& Hazlitt, H. (1984). The wisdom of the stoics: Selections from seneca, epictetus, and MarcusAurelius. Lanham, MD: University Press of America.

Heifetz, R. A. (1994). Leadership without easy answers. Cambridge, Mass: Belknap Press of Harvard University Press.

Heifetz, R. A., \& Laurie, D. L. (2001). The work of leadership. Harvard Business Review: Best of HBR.

Heifetz, R. A., \& Linsky, M. (2002). A survival guide for leaders. Harvard Business School Publishing.

Kotter, J. P. (1995). Leading change: Why transformation efforts fail. Boston, MA:Harvard Business School Publishing.

Mulford, P. (1886). Your forces and how to use them. YoGeBooks: Hollister.

Palanski, M. E., \& Yammarino, F. J. (2009). Integrity and leadership: A multi-level conceptual framework. The Leadership Quarterly, 20(3), 405-420.

Tolstoy, L. (1903). Three questions. New York: Scholastic Press.

Tracy, B. (2005). Change your thinking, change your life. Hoboken, NJ: John Wiley\& Sons.

Ury, W. (1993). Getting past no: Negotiating in difficult situations ( $2^{\text {nd }}$ ed.). NY: Bantam Dell Books. 